medRxiv preprint doi: https://doi.org/10.1101/2021.08.19.21262272; this version posted August 25, 2021. The copyright holder for this preprint (which was not certified by peer review) is the author/funder, who has granted medRxiv a license to display the preprint in perpetuity.

It is made available under a CC-BY 4.0 International license.

1 Article Summary Line: Potential impact of Anopheles stephensi establishment on the transmission of falciparum malaria in Ethiopia and prospective control measures.

$3 \quad$ Running title (50 characters): Impact of Anopheles stephensi in Ethiopia

4

5

6

Keywords: Anopheles stephensi, Indoor residual spraying, Larval source management, Insecticide treated nets, invasive mosquito, Ethiopia, Djibouti,

\title{
The potential impact of Anopheles stephensi establishment on the transmission of Plasmodium falciparum in Ethiopia and prospective control measures
}

Arran Hamlet $^{1 *}$, Dereje Dengela ${ }^{2}$, J. Eric Tongren ${ }^{3,4}$, Fitsum G Tadesse ${ }^{5,6}$, Teun Bousema ${ }^{6,7}$, Marianne Sinka ${ }^{8}$, Aklilu Seyoum ${ }^{2}$, Seth R. Irish ${ }^{9}$, Jennifer S. Armistead ${ }^{10}$ and Thomas Churcher $^{1}$

${ }^{1}$ MRC Centre for Global Infectious Disease Analysis; and the Abdul Latif Jameel Institute for Disease and Emergency Analytics, School of Public Health, Imperial College London, London, UK

${ }^{2}$ PMI VectorLink Project, Abt Associates, 6130 Executive Blvd, Rockville, MD 20852, USA.

${ }^{3}$ US President's Malaria Initiative (PMI), Addis Ababa, Ethiopia.

${ }^{4}$ Malaria Branch, Division of Parasitic Diseases and Malaria, Center for Global Health, Centers for Disease Control and Prevention, Atlanta, GA, USA.

${ }^{5}$ Armauer Hansen Research Institute, Addis Ababa, Ethiopia.

${ }^{6}$ Radboud Institute for Health Sciences, Radboud University Medical Center, Nijmegen, The Netherlands.

${ }^{7}$ Department of Immunology and Infection, London School of Hygiene and Tropical Medicine, London, UK.

${ }^{8}$ Department of Zoology, University of Oxford, Oxford, United Kingdom, OX1 3SZ

${ }^{9}$ US President's Malaria Initiative, Entomology Branch Division of Parasitic Diseases and Malaria, Center for Global Health, Centers for Disease Control and Prevention, Atlanta, GA, USA.

${ }^{10}$ U.S. President's Malaria Initiative, U.S. Agency for International Development, Washington, D.C., USA

*Corresponding author - arran.hamlet14@ imperial.ac.uk

\section{Abstract (149 words of 150 words)}

Anopheles stephensi, the primary urban malaria vector in Asia, was first detected in Africa during 2012 in Djibouti and was subsequently identified in Ethiopia in 2016, and later in Sudan and Somalia. In Djibouti, malaria cases have increased 30-fold from 2012 to 2019 though the impact in the wider region remains unclear.

A mechanistic model of malaria transmission was used to estimate the increase in vector density required to explain the trends in malaria cases seen in Djibouti. Applying this vector density to Ethiopia, we assess the potential impact of An. stephensi establishment on Plasmodium falciparum transmission, accounting for pre-existing transmission and control inOTE: This preprint reports new research that has not been certified by peer review and should not be used to guide clinical practice. 
medRxiv preprint doi: https://doi.org/10.1101/2021.08.19.21262272; this version posted August 25, 2021. The copyright holder for this preprint (which was not certified by peer review) is the author/funder, who has granted medRxiv a license to display the preprint in It is made available under a CC-BY 4.0 International license.

42 We estimate that annual P. falciparum malaria cases could increase by 50\% (95\% CI 14-90) if 43 no additional interventions are implemented. Substantial heterogeneity across the country is 44 predicted and large increases in vector control interventions could be needed to prevent a major 45 public health emergency. 
medRxiv preprint doi: https://doi.org/10.1101/2021.08.19.21262272; this version posted August 25, 2021. The copyright holder for this preprint (which was not certified by peer review) is the author/funder, who has granted medRxiv a license to display the preprint in perpetuity.
It is made available under a CC-BY 4.0 International license.

\section{Text word count (3482 of 3500 words)}

\section{Introduction}

48 Sub-Saharan Africa, where $94 \%$ of the global malaria burden occurs, has seen substantial 49 reductions in cases and deaths due to malaria over the past two decades (1). While this 50 reduction is primarily due to an increase in investments and expansion of interventions such as 51 insecticide treated nets (ITNs), indoor residual spraying (IRS), and diagnosis and treatment, 52 urbanisation also has a played a part.

53 Africa has experienced rapid urbanization in recent years, rising from $31.5 \%$ of the population 54 in 1990 , to $42.5 \%$ in 2018 . By 2050 , approximately $60 \%$ of the population is expected to live 55 in urban areas (2). This will likely have a positive effect on reducing the malaria burden in 56 Africa, as urban areas typically experience substantially lower rates of malaria transmission 57 than rural areas (3). Primarily, this is thought to be due to improved housing and the reduced 58 availability of suitable larval habitats for African Anopheles vector species (4).

This protective effect conferred by urbanization may be partially lost with the invasion and establishment of Anopheles stephensi. Anopheles stephensi is found throughout South Asia, where it is capable of transmitting both Plasmodium falciparum and $P$. vivax parasites (5) in a diverse set of habitats, from rural to highly urban settings (6). The success of this vector in urban locations is due to its ability to utilise water tanks, wells, and other artificial containers as larval habitats $(7,8)$. Furthermore, it has shown substantial resistance to water pollution (9). An. stephensi has been discovered at locations further outside of its traditional endemic region in Asia, and was first detected in Djibouti in 2012 (10).

Prior to 2013, Djibouti had reported less than 3000 cases per year. Following the year of initial detection of An. stephensi, malaria cases have increased substantially, and in 2019 there were 49,402 confirmed cases of malaria (11). While causation has not been established between increasing An. stephensi detection and malaria incidence in Djibouti, it has been heavily implicated (12). Anopheles stephensi has now been found in Sudan, Somalia, and Ethiopia (13).

Here we quantify the potential impact of An. stephensi invasion in Djibouti to make projections about what could happen in Ethiopia, where the species has been found in numerous sites and is spreading (14). Translating the invasion of An. stephensi to its public health impact is difficult due to uncertainty in its vectoral capacity and how public health entities and governments will respond. Different illustrative scenarios are investigated, exploring the public health impact of different vector control interventions. 
Methods

\section{Mechanistic malaria model}

80

81

82

83

84

85

86

87

88

89

90

91

92

93

94

95

96

97

98

99

100

101

102

103

104

105

106

107

108

109

110

111

112

113

114

115

116

117

A deterministic version of a well-established compartmental model of $P$. falciparum malaria transmission (15-19) was utilised. The human population was split into susceptible or infected individuals with those infected being either asymptomatic, having clinical disease, submicroscopic infections, having been treated, or being in a period of prophylaxis following treatment. The numbers of mosquito larvae, pupae and adults were simulated with adult mosquitoes being either susceptible, exposed, or infectious (after the extrinsic incubation period, EIP). The model accounts for heterogeneity in transmission as well as age-dependent mosquito biting rates and the acquisition of natural immunity. The model is summarised in Appendix Figure 1 and accompanying text with code found at https://github.com/mrcide/deterministic-malaria-model.

\section{Vector bionomics and Latin hypercube sampling}

The epidemiological impact of An. stephensi invasion will depend on the characteristics of the vector in the new environment. Vector behaviours such as crepuscular biting, and resting outside of houses could translate, compared to other African Anopheles species, to a reduced efficacy of interventions such as ITN and IRS, and therefore accurate parameterisation is important. A literature search was undertaken to find An. stephensi-specific bionomic data to parameterise the mechanistic model. These included the daily mortality, proportion of blood meals taken on humans, anthropophily (the preference of the vector to biting humans over other sources), bites taken indoors and in sleeping spaces. The impact of these is further explored in Appendix Figure 7 and the accompanying text. Data on An. stephensi behaviour within Africa was sparse, and so estimates were primarily acquired from studies in Iran, India and Pakistan, with limited data from Ethiopia. A full list of studies and parameter range estimates are in the Appendix Table 1 and Appendix Table 5.

Due to the relatively low number of studies from which the data were collected, and large uncertainty around how the vector would behave, we incorporated parameter sampling in the model fitting and extrapolation stage. This was done through taking the median value from the data, and sampling from values $25 \%$ smaller and $25 \%$ larger unless otherwise stated (Appendix Table 1). From this we undertook Latin hypercube sampling (LHS) which is a statistical method for generating near-random samples of parameter values from a multidimensional distribution. This allowed us to efficiently sample different parameter combinations in order to generate broad uncertainty in predictions (20).

The efficacy of current and future ITNs will also depend on the level of pyrethroid resistance. Substantial pyrethroid resistance has been found in Ethiopia, with a mean across years and sites of 57\% mosquito survival upon exposure to pyrethroids in a discriminating dose bioassay (14). This value was assumed throughout the country. There is no clear picture of how An. stephensi abundance will change seasonally in Ethiopia, and so mosquito density was assumed to remain consistent throughout the year. Ethiopia is geographically diverse, with many regions at high altitudes, reducing malaria transmission. The relationship of the extrinsic incubation period and 
118 temperature were provided from Stopard et al. (2021) (21). How this influences transmission

119 is outlined in the Appendix Figure 3 and 6.

\section{Fitting to Djibouti data}

121 The severity of the public health impact of An. stephensi invasion will depend on the number of mosquitoes per person (vector density) and how it changes over time. In the absence of information on the speed and magnitude of An. stephensi establishment in Ethiopia, we made the simplest assumption that density increases in a sigmoidal manner that mirrors what has happened in Djibouti. Here, given the low levels of malaria reported prior to An. stephensi detection we assumed that the increase is singly due to An. stephensi, though native Anopheles species such as An. arabiensis are present. This process is conducted in conjunction with 200 LHS parameterisations of vector bionomics. From this, we take the 100 best LHS combinations, as defined by their likelihood, and calculate the 2.5, 50 and $97.5 \%$ quantiles. This provides us with estimates of the vector density required to explain malaria incidence in Djibouti (Appendix Figure 4). We then take the vector density required to explain the final year where it appears to have plateaued, 2019, and apply this to Ethiopia.

\section{Current level of disease}

135 Estimates of the geographical distribution of malaria within Ethiopia were generated from malaria slide prevalence in 2-10-year-olds estimates extracted using the Malaria Atlas Project (MAP) R package, malariaAtlas (22). These were aggregated to the 3rd administrative division (woreda) using a population weighted mean. Estimates were adjusted so that the number of cases predicted by the model matched those reported in the World Malaria Report (WMR). In 2019 (the last year data were available) a total of 738,155 cases of $P$. falciparum malaria were reported in Ethiopia. Here we concentrate on falciparum malaria as this is the dominant malaria species with the biggest public health impact. ITN usage was provided at the $1^{\text {st }}$ administrative division (region) assuming pyrethroid-only ITNs, and IRS coverage at the woreda level (23). Human population sizes were taken from UN World Population Prospects (24). Historical use of antimalarial drug treatment was also extracted from malariaAtlas. In order to reduce computational demands, prevalence was rounded to $0,1,5,10,15,25 \%$, ITN/IRS/treatment to the nearest $20 \%$, and EIP the nearest 1 . This reduced the number of administrative locations considered from $6903^{\text {rd }}$ administrative (woreda) units to 64 administrative groupings (see Appendix).

\section{Projections of future malaria burden}

Models were used to project the change in malaria prevalence over time following the invasion of An. stephensi. Here, we assumed an equal and simultaneous introduction in all groupings, which while unrealistic is the most parsimonious response (see Appendix). Simulations were run for each administrative grouping. It is likely that An. stephensi will not invade all regions of the country (25), and that invasion in areas above an altitude of $2000 \mathrm{~m}$ is unlikely to result in an increased malaria burden due to the low temperatures. We therefore estimated the increase in the number of malaria cases in the population within areas found suitable by previous research (25), and beneath 2000 meters (26). 
medRxiv preprint doi: https://doi.org/10.1101/2021.08.19.21262272; this version posted August 25, 2021. The copyright holder for this preprint (which was not certified by peer review) is the author/funder, who has granted medRxiv a license to display the preprint in

perpetuity.
It is made available under a CC-BY 4.0 International license .

160 Different vector control interventions are considered to mitigate the impact of An. stephensi

161 invasion. As possible scenarios, we investigated the potential impact of increasing ITN usage,

162 deploying IRS and larval source management (LSM). ITN usage was increased from its current

163 level (Appendix Figure 2) up to 80\% usage assuming mass distribution every 3-years

164 (assuming pyrethroid-only ITNs). For the implementation of synergist piperonyl butoxide

165 (PBO) via PBO-pyrethroid ITNs, a current usage of $0 \%$ was assumed and scale-up involved

166 replacing all existing standard pyrethroid-only ITNs. Pyrethroid-only and PBO-pyrethroid

167 ITNs decline in efficacy over their lifespan as detailed in Churcher et al., (2016)(27). In costing

168 future interventions, we subtracted the cost of existing ITN coverage, as we were calculating

169 the additional cost. IRS covering $80 \%$ of structures of human habitation is conducted annually

170 with a long-lasting product which the local mosquito population is fully susceptible to; this

171 decays throughout the year as previously described (28). The impact of LSM against

172 An. stephensi is highly unclear but in the absence of this information it was assumed to be

173 constant and at a level to reduce adult emergence by $40 \%$. To illustrate the broad economic

174 cost of this additional vector control, simple estimates of total costs are provided. Approximate

175 estimates of the cost of intervention (purchasing, delivering, and applying) were provided from

176 literature and from the U.S. President's Malaria Initiative (Appendix Table 3). 


\section{$178 \quad$ Results}

\section{Projected changes in malaria epidemiology}

180 The establishment of An. stephensi is predicted to increase the malaria burden across Ethiopia according to pre-existing transmission levels, interventions and vector bionomics. As an example, three locations at very low $(\sim 0.1 \%)$, low $(\sim 2.5 \%)$ and moderate $(\sim 12 \%)$ current $P$. falciparum prevalence are displayed (Figure 2). In all example locations, the introduction of An. stephensi leads to increased prevalence, with the most substantial increases in areas with the lowest existing transmission $(\sim 0.1 \%)$, though estimates are highly uncertain (Figure 1A). The rate at which prevalence increases depends on the current levels of transmission, with areas at current negligible levels of transmission taking substantially longer than those areas with current moderate-high transmission to reach the new level of endemicity after mosquito establishment. Sub-nationally, there is considerable variation in the projected increases in prevalence, with some administrative groupings experiencing minimal ( $0 \%)$ increases to absolute prevalence following An. stephensi establishment, and others increasing by $\sim 5.5 \%$ (Figure 1B). Overall, the median absolute parasite prevalence increase is $\sim 3.4 \%$ in administrative regions, an increase from $\sim 1.2 \%$ pre-An. stephensi to $4.6 \%$ post-An. stephensi. At a national level, we predict a median increase of $\sim 368,000$ (95\% CI 103,000 - 664,000) clinical P. falciparum malaria cases annually, from a report of $\sim 740,000$ in 2019 (1). This represents a $49.7 \%$ (95\% CI 13.9 - 89.7\%) increase if An. stephensi only establishes itself in areas previously found suitable, and located under 2000m (Error! Reference source not found.C). Substantially greater increases are seen if An. stephensi invades the whole country and can establish malaria transmission at higher altitudes (Appendix Table 4). Temporal changes in clinical incidence over time for the different settings are shown in Figure 2. Some model runs predicted a substantial increase in malaria cases following a subsequent decline over time. This phenomenon is greatest in areas with the lowest current malaria prevalence and is driven by the model assumptions on the acquisition of immunity to clinical disease.

\section{Impact of increasing vector control}

205 The impact of additional vector control interventions following An. stephensi establishment is dependent on the level of transmission, pre-existing use of interventions and vector bionomics. Mosquito characteristics such as the proportion of bites taken indoors are unknown and can substantially influence the effectiveness of ITNs and IRS (Appendix Table 5, Figure 7 and accompanying text). In some circumstances the model predicts that scaling up of standard ITNs, IRS or LSM in combination is sufficient to suppress malaria to pre-An. stephensi levels, and sometimes beyond (Figure 2A).

In areas with low levels of transmission $(\sim 0.1 \%)$, increases in incidence are substantial, and in order to reduce transmission to pre-An. stephensi levels of transmission, a suite of interventions must be considered (Figure 2B). At higher levels of transmission $(\sim 12 \%)$, the implementation of PBO-ITNs alone may be suitable to reduce, however if only pyrethroid-ITNs are available, they should be used in conjunction with IRS and LSM to reduce transmission to pre-An. stephensi levels (Figure 2B). The efficacy of LSM in the area is highly unclear, but a $40 \%$ reduction in mosquito emergence is predicted to have a larger impact in areas of lower 
endemicity; conversely, ITNs are predicted to be more effective at higher endemicities. The extent of IRS impact is unclear. Overall, we find that if using standard pyrethroid-only ITNs, a combination of ITN/IRS/LSM is needed to reduce national $P$. falciparum incidence to preAn. stephensi levels. However, given the unknowns in An. stephensi responses to these interventions, even this may be insufficient (Table 1, Figure 2B).

The mass distribution of PBO-pyrethroid nets may offer a more cost-effective tool given the high levels of pyrethroid resistance and relatively low levels of endophily in Ethiopian $A n$. stephensi populations (Figure 2 and Table 1). PBO-pyrethroid nets are predicted to have the most substantial impact on transmission of any single intervention examined, and almost achieves the reduction provided by a combination of standard ITNs, IRS and LSM $(139,000$ (60,000-157,000) vs 194,000 (44,000-410,000) cases averted). Furthermore, PBO-pyrethroid nets only account for a fraction of the cost of this more comprehensive intervention packet, \$3.5 (2.9-3.7) vs \$70.3 million USD (38.4-100.9).

Layering multiple vector control interventions are predicted to have the largest impact. However, because of the number of sites with minimal malaria transmission before $A n$. stephensi invasion, this may be insufficient to push the national malaria burden beneath current levels unless PBO-pyrethroid nets, higher coverage (ITNs, IRS) or improved effectiveness (LSM) can be achieved (Table 1). Increases in IRS coverage to $80 \%$ alone offers substantial improvements due to the relatively limited use of IRS currently nationwide (Appendix Figure 2). However, due to low rates of endophily and crepuscular biting, the impact is substantially less than would be expected against African Anopheles species. The cost of implementing interventions is expected to be substantial, with the most comprehensive set of interventions (80\% use of PBO-pyrethroid ITN and IRS, $40 \%$ reduction in adult emergence) estimated to cost an additional \$72.0 million USD (\$39.9 - \$102.5 million) annually or \$238.5 USD (\$132.1-\$339.4) per case averted (over existing malaria prevention budgets).

\section{Discussion}

The invasion and establishment of Anopheles stephensi represents an imminent and substantial threat to the Horn of Africa and wider region which could jeopardize progress achieved in malaria control. The modeled increase in malaria is highly uncertain, but without additional interventions, the impact could be considerable, with an estimated $\sim 50 \%$ increase from the reported $\sim 740,000$ P. falciparum malaria cases in Ethiopia, 2019, to an estimated 1,130,000 (95\% CI 843,000-1,404,000) after establishment and disease equilibrium has been reached. This assumes that malaria cases only increase in areas previously predicted as suitable for An. stephensi establishment located under $2000 \mathrm{~m}$. Numbers could be substantially higher if invasion is more widespread.

Sub-nationally, significant heterogeneity in public health impact is expected. Analysis suggests that low altitude urban areas that currently experience negligible malaria transmission may experience the largest increases in disease burden. In these areas, the absence of existing vector control and low human population immunity indicates the possibility for substantial increases in transmission. Our finding that areas with low pre-existing levels of transmission (much of 
Ethiopia) take substantially longer to see increases in malaria after An. stephensi introduction is particularly worrying. In these locations, in the absence of widespread and routine surveillance for An. stephensi, the first signal detected could be an increase in malaria, which would occur a considerable amount of time after mosquito establishment. While this would not be of significant concern if the vector was easily removed, or only led to a relatively minor and easily combatable increase in malaria, our model findings and what has been observed in Djibouti $(11,12)$ suggest that this is not the case. Once An. stephensi becomes established, it could lead to significant increases in malaria transmission that are not easily reversed. This unnoticed proliferation and subsequent increase in transmission was previously seen in Anopheles arabiensis in North-Eastern Brazil, where its "silent spread" led to a large malaria epidemic $(25,29)$. Nevertheless, this work shows that the absence of an increase in reported malaria cases following the identification of the presence of An. stephensi should not be overly interpreted.

To combat the possible increase of malaria transmission following An. stephensi establishment, the deployment of a wide array of vector control interventions should be considered. High levels of pyrethroid resistance observed in An. stephensi captured in Ethiopia $(14,30)$ suggest that pyrethroid-only ITNs (already in use across the country) will have a limited efficacy for control of malaria transmitted by An. stephensi. Adoption of PBO-ITNs is predicted to be both highly impactful and cost-effective. The impact of different control interventions is unclear given the receptiveness of An. stephensi in this new environment is unquantified. For example, if the mosquito feeds at night and rests inside structures sprayed with IRS then the widespread use of this intervention alone could be sufficient to mitigate the public health impact (Appendix Table 5, Figure 7 and accompanying text). However, if the mosquito was less amenable to indoor vector control, then layering of ITNs and IRS may be insufficient. Within its endemic range, An. stephensi shows a propensity to both crepuscular biting and resting outside of houses compared to African Anopheles species, suggesting a reduced efficacy if it behaves as it does in its endemic range (25) (Appendix Table 6). Compounding this, high density urban locations, where large scale vector-control campaigns have been historically absent, will present a challenge for establishing ITN access and use, as well as achieving sufficient IRS coverage. Additional data on An. stephensi bionomics and the impact of vector control interventions should therefore be collected as a matter of urgency to enable model estimates to be refined and contribute to the decision-making process, (see Appendix). These compound uncertainties combined with the crude method of economic evaluation adopted here make cost projections highly variable. Though these are substantial (\$74.6 million USD (\$42.6 - \$105.4)), the economic burden of an additional $\sim 368,000(95 \%$ CI $103,000-664,000)$ malaria cases should not be underestimated.

This work was intended to provide initial estimates of the possible scale and impact of $A n$. stephensi invasion rather than detailed predictions of what will happen. As such, there are many limitations to this approach (further detailed in the Appendix) and results should not be overly interpreted. The public health impact is likely to be underestimated as we only consider P. falciparum malaria, despite An. stephensi having been shown to be capable of efficiently transmitting P. vivax in Ethiopia (31). Due to the presence of additional Anopheles species in Djibouti, it is unlikely the increases we have seen are purely due to An. stephensi, which we 
medRxiv preprint doi: https://doi.org/10.1101/2021.08.19.21262272; this version posted August 25, 2021. The copyright holder for this preprint (which was not certified by peer review) is the author/funder, who has granted medRxiv a license to display the preprint in

perpetuity.
It is made available under a CC-BY 4.0 International license.

303 have assumed, and while highly correlated (11), and increasingly implicated (12), the causative

304 role in An. stephensi in the increases seen in Djibouti has not been established. However, the 305 trends observed along with evidence of underreporting in Djibouti are cause for significant 306 concern. Malaria burden is related to the extent to which An. stephensi may invade a region 307 (i.e., the number of mosquitoes per person and not just its presence). While we have made use 308 of available published and unpublished sources on An. stephensi bionomics in its endemic 309 range, there is either insufficient data or substantial intra-species variability to simply ascribe 310 a set of characteristics to how An. stephensi will interact with humans and control interventions 311 in Ethiopia. In order to improve predictions, we have identified priority aspects of An. stephensi 312 bionomics (such as anthropophagy, endophily, indoor biting), local transmission (existing 313 distribution of malaria cases between rural and urban areas) and intervention parameters

314 (efficacy of ITNs, IRS and LSM give a certain effort) that should be explored as a priority in 315 order to inform additional mathematical modelling of the impact of An. stephensi on malaria 316 transmission in Africa (see Appendix).

317 While there is substantial uncertainty in what will happen if An. stephensi becomes established 318 in Ethiopia and other locations across Africa, the estimates provided here, and the situation 319 seen in Djibouti, should be a stark warning against complacency and highlight the need to 320 rapidly improve surveillance and evaluate effective control interventions in response to this 321 developing threat. 
medRxiv preprint doi: https://doi.org/10.1101/2021.08.19.21262272; this version posted August 25, 2021. The copyright holder for this preprint (which was not certified by peer review) is the author/funder, who has granted medRxiv a license to display the preprint in perpetuity.
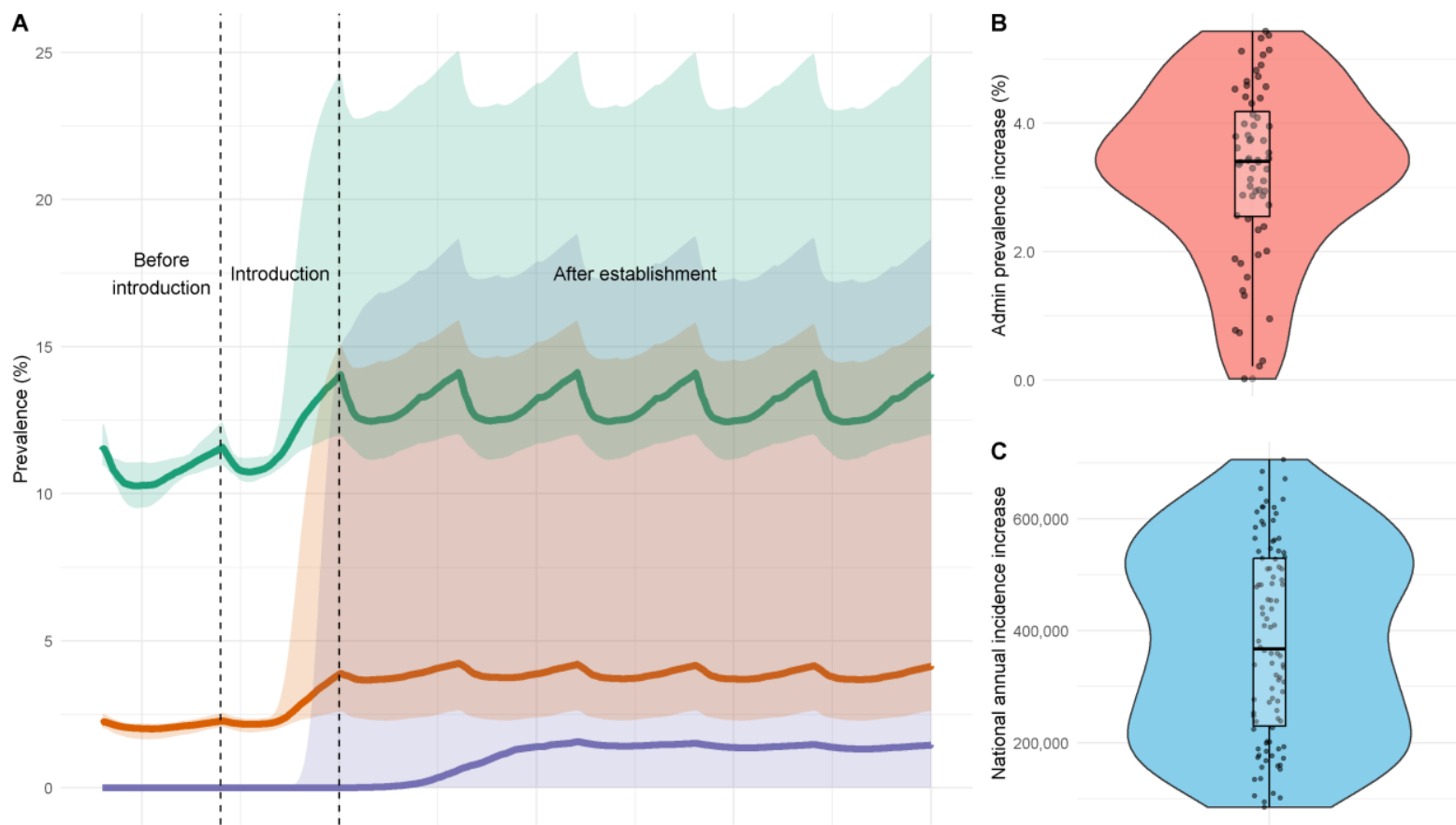

Figure 1. The impact of An. stephensi introduction on malaria prevalence and incidence in areas of Ethiopia in areas under $2000 \mathrm{~m}$ and identified to be suitable. A) Changes in prevalence following introduction and establishment of An. stephensi in 3 areas of malaria transmission in Ethiopia. Vertical dashed lines span the period in which An. stephensi is introduced and coloured shapes the 95\% CI's. Green represents a transmission scenario of $\sim 12 \%$ prevalence, orange, $2.5 \%$, and purple $<0.1 \%$ B) The median difference of $P$. falciparum prevalence following establishment in the different administrative groupings which have been predicted to be suitable based on Sinka et al., (2020) and under 2000m. C) The annual increase in clinical incidence of malaria caused by $P$. falciparum nationally. Individual dots show uncertainty in predictions given differences in mosquito bionomics (for 100 samples of the Latin hyper cube). Periodicity is caused by ongoing distribution of ITNs and IRS which are assumed to continue at pre-invasion levels. 
A

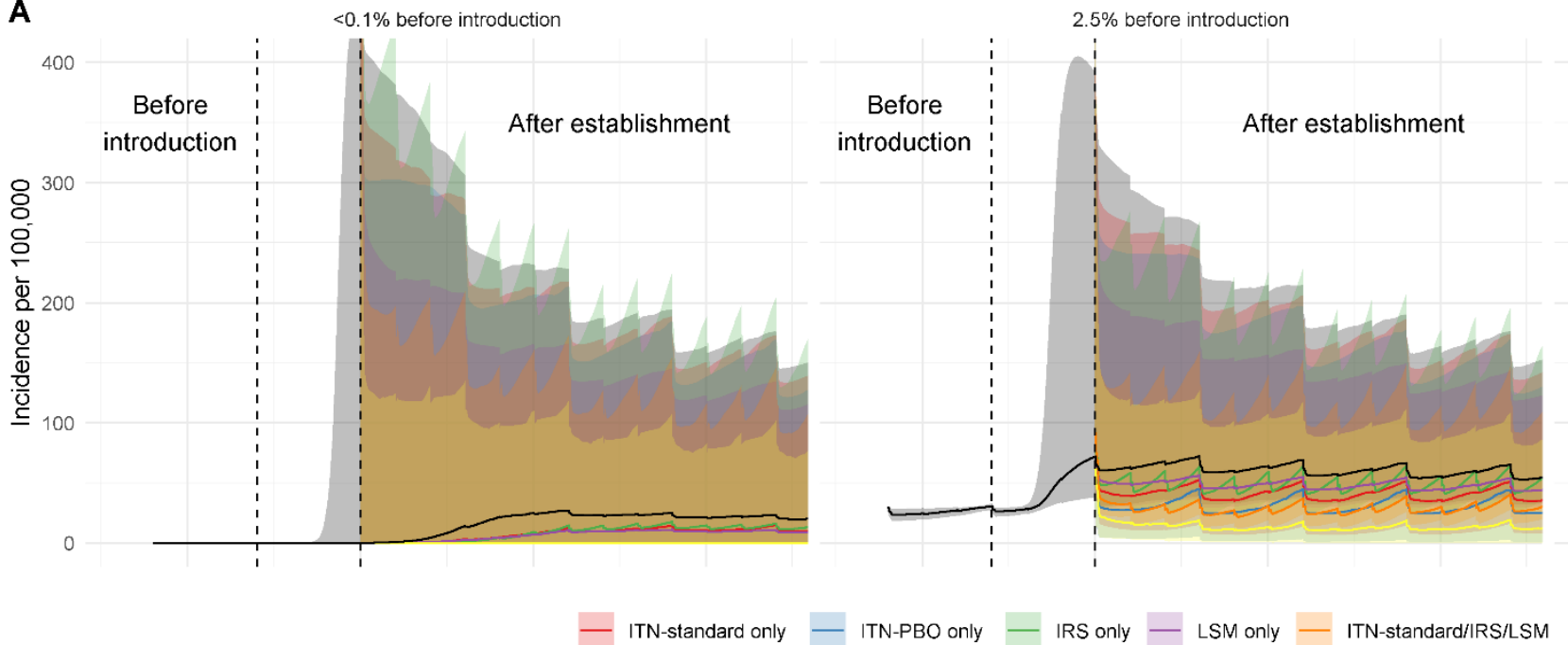

B

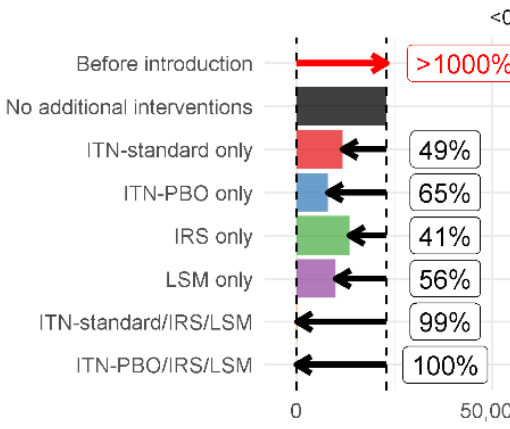

$0.1 \%$ pefore introduction

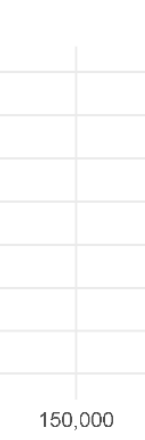

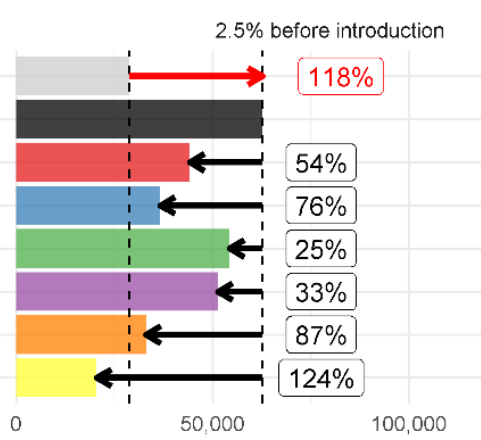

Annual incidence per 1000000

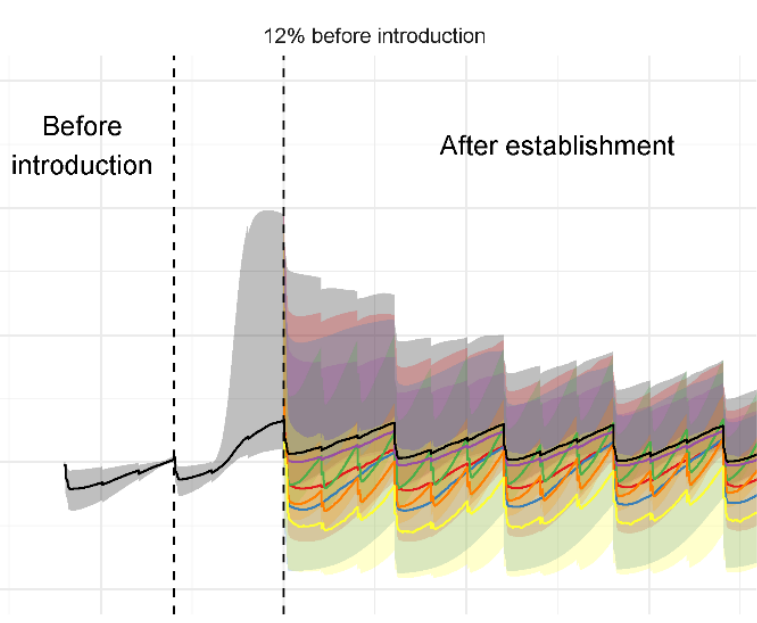

ITN-PBO/RS/LSM

Figure 2. The effect of control measures on mitigating the impact of An. stephensi introduction for regions with different pre-existing malaria endemicity. A) The change in clinical incidence over time (per 100,000 people per year) following An. stephensi introduction in three locations, with low $(\sim 0.1 \%)$, medium $(\sim 2.5 \%)$ and high slide prevalence $(\sim 12 \%)$. Each location had an EIP of 8 and $40 \%$ ITN coverage, $0 \%$ IRS and 0\% LSM pre-An. stephensi introduction and establishment. Different coloured lines indicate intervention scenarios be it no additional interventions (black), or scale up of ITNs (to $80 \%$ use, red), IRS (to $80 \%$, blue), the use of LSM (reducing mosquito emergence by $40 \%$, green) or the use of all three (at previous levels, purple). Coloured shapes show the $95 \%$ CIs for model predictions given uncertainty in parameters. The left 
vertical dashed line indicates the start to the introduction of An. stephensi, which occurs between the dashed lines and is fully established by year 3. B) The median annual increase in malaria incidence per 100,000 per year comparing before and after scenarios for each of the locations across a range of intervention combinations. Red arrows and numbers refer to the percentage increase in the median incidence following the establishment of An. stephensi compared to the 3 years prior to the introduction. Black lines and numbers show the percentage reduction in cases relative to no additional interventions over three years caused by the introduction of the different control interventions. 
medRxiv preprint doi: https://doi.org/10.1101/2021.08.19.21262272; this version posted August 25, 2021. The copyright holder for this preprint (which was not certified by peer review) is the author/funder, who has granted medRxiv a license to display the preprint in perpetuity.

It is made available under a CC-BY 4.0 International license .

Table 1. Different combinations of ITN/ITN-PBO/IRS/LSM and the associated annual cases averted and costs, total and per person. ITN/ITN-PBO/IRS values refer to the coverage among the population exposed to An. stephensi introduction and LSM the reduction in adult emergence of the established An. stephensi. Values in brackets for the cases averted refer to the difference in minimum and maximum 95\% CI's and as such the cases averted median value does not always fall within this, or in numerical order. Total costs and costs per case refer to the median cases averted, and the range in the brackets as the minimum and maximum costs defined in the Appendix.

\section{ITN ITN- IRS LSM PBO \\ Cases averted (thousands)}

\section{Total costs (million USD)}

\section{Cost per case} averted

(USD)

\begin{tabular}{|c|c|c|c|c|c|c|}
\hline $0 \%$ & & $0 \%$ & $40 \%$ & $68(9-143)$ & $9.9(5.0-14.9)$ & $18(9-27)$ \\
\hline $80 \%$ & & $0 \%$ & $0 \%$ & $71(29-31)$ & $1.8(1.7-1.9)$ & $3(3-3)$ \\
\hline $0 \%$ & & $80 \%$ & $0 \%$ & $75(16-99)$ & $58.6(31.7-84.2)$ & $96(52-138)$ \\
\hline $80 \%$ & & $80 \%$ & $40 \%$ & $172(39-301)$ & $70.3(38.4-100.9)$ & $50(27-72)$ \\
\hline & $80 \%$ & $0 \%$ & $0 \%$ & $139(60-157)$ & $3.5(2.9-3.7)$ & $25(21-27)$ \\
\hline & $80 \%$ & $80 \%$ & & $207(70-33)$ & $64.6(37.2-90.8)$ & $91(52-127)$ \\
\hline & $80 \%$ & & $80 \%$ & $210(49-361)$ & $16.0(10.6-21.5)$ & $22(15-30)$ \\
\hline & $80 \%$ & $80 \%$ & $40 \%$ & $302(79-879)$ & $72.0(39.9-102.5)$ & $239(132-339)$ \\
\hline
\end{tabular}


medRxiv preprint doi: https://doi.org/10.1101/2021.08.19.21262272; this version posted August 25, 2021. The copyright holder for this preprint (which was not certified by peer review) is the author/funder, who has granted medRxiv a license to display the preprint in perpetuity.

It is made available under a CC-BY 4.0 International license .

\section{Acknowledgements}

We acknowledge funding support from the United States President's Malaria Initiative and the MRC Centre for Global Infectious Disease Analysis (reference MR/R015600/1). The MRC Centre for Global Infectious Disease Analysis is jointly funded by the UK Medical Research Council (MRC) and the UK Foreign, Commonwealth \& Development Office (FCDO), under the MRC/FCDO Concordat agreement and is also part of the EDCTP2 programme supported by the European Union; and acknowledges funding by Community Jameel. The findings and conclusions in this report are those of the author(s) and do not necessarily represent the official position of the Centers for Disease Control and Prevention or the U.S. President's Malaria Initiative.

\section{Author Bio (first author only)}

Dr Arran Hamlet is a mathematical modeller of infectious disease in the MRC Centre for Global Infectious Disease Epidemiology at Imperial College London. His research interests include the application of mathematical and statistical modelling to further understand the epidemiology of vector-borne diseases and the impact of control measures against them. 
medRxiv preprint doi: https://doi.org/10.1101/2021.08.19.21262272; this version posted August 25, 2021. The copyright holder for this preprint (which was not certified by peer review) is the author/funder, who has granted medRxiv a license to display the preprint in

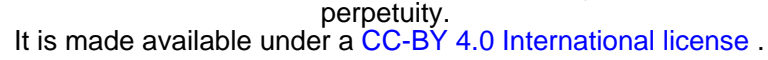

\section{References}

1. World Health Organization. World malaria report 2020: 20 years of global progress and challenges,. Geneva: World Health Organization; 2020.

2. United Nations. DoEaSA, Population Division. World Urbanization Prospects: The 2018 Revision (ST/ESA/SER.A/420). New York: United Nations; 2019.

3. Hay SI, Guerra CA, Tatem AJ, Atkinson PM, Snow RW. Urbanization, malaria transmission and disease burden in Africa. Nat Rev Microbiol. 2005 Jan;3(1):81-90.

4. Trape JF, Zoulani A. Malaria and urbanization in central Africa: the example of Brazzaville. Part III: Relationships between urbanization and the intensity of malaria transmission. Trans R Soc Trop Med Hyg. 1987;81 Suppl 2:19-25.

5. Thomas S, Ravishankaran S, Justin NA, Asokan A, Mathai MT, Valecha N, et al. Resting and feeding preferences of Anopheles stephensi in an urban setting, perennial for malaria. Malar J. 2017 Mar 10;16(1):111.

6. Subbarao SK, Nanda N, Rahi M, Raghavendra K. Biology and bionomics of malaria vectors in India: existing information and what more needs to be known for strategizing elimination of malaria. Malar J. 2019 Dec 3;18(1):396.

7. Kumar A, Thavaselvam D. Breeding habitats and their contribution to Anopheles stephensi in Panaji. Indian J Malariol. 1992 1992/03//;29(1):35-40.

8. Gayan Dharmasiri AG, Perera AY, Harishchandra J, Herath H, Aravindan K, Jayasooriya HTR, et al. First record of Anopheles stephensi in Sri Lanka: a potential challenge for prevention of malaria reintroduction. Malaria J. 2017 2017/08/10;16(1):326.

9. Batra CP, Adak T, Sharma VP, Mittal PK. Impact of urbanization on bionomics of An. culicifacies and An. stephensi in Delhi. Indian J Malariol. 2001 Sep-Dec;38(3-4):61-75.

10. Faulde MK, Rueda LM, Khaireh BA. First record of the Asian malaria vector Anopheles stephensi and its possible role in the resurgence of malaria in Djibouti, Horn of Africa. Acta tropica. 2014 Nov;139:39-43.

11. Seyfarth M, Khaireh BA, Abdi AA, Bouh SM, Faulde MK. Five years following first detection of Anopheles stephensi (Diptera: Culicidae) in Djibouti, Horn of Africa: populations established-malaria emerging. Parasitol Res. 2019 Mar;118(3):725-32.

12. de Santi VP, Khaireh BA, Chiniard T, Pradines B, Taudon N, Larreche S, et al. Role of Anopheles stephensi Mosquitoes in Malaria Outbreak, Djibouti, 2019. Emerging infectious diseases. 2021;27(6):1697-700.

13. World Health Organization. Malaria Threat Map. 2021 [cited 28/06/21]; Available from: 14. Balkew M, Mumba P, Yohannes G, Abiy E, Getachew D, Yared S, et al. An update on the distribution, bionomics, and insecticide susceptibility of Anopheles stephensi in Ethiopia, 2018-2020. Malar J. 2021 Jun 9;20(1):263.

15. Griffin JT, Ferguson NM, Ghani AC. Estimates of the changing age-burden of Plasmodium falciparum malaria disease in sub-Saharan Africa. Nature communications. 2014;5:3136.

16. Challenger JD, Olivera Mesa D, Da DF, Yerbanga RS, Lefèvre T, Cohuet A, et al. Predicting the public health impact of a malaria transmission-blocking vaccine. Nature communications. 2021 2021/03/08;12(1):1494.

17. Griffin JT, Hollingsworth TD, Okell LC, Churcher TS, White M, Hinsley W, et al. Reducing Plasmodium falciparum malaria transmission in Africa: a model-based evaluation of intervention strategies. PLoS medicine. 2010 Aug 10;7(8).

18. White MT, Griffin JT, Churcher TS, Ferguson NM, Basanez MG, Ghani AC. Modelling the impact of vector control interventions on Anopheles gambiae population dynamics. Parasites \& vectors. $2011 \mathrm{Jul}$ 28;4:153.

19. Griffin JT, Bhatt S, Sinka ME, Gething PW, Lynch M, Patouillard E, et al. Potential for reduction of burden and local elimination of malaria by reducing Plasmodium falciparum malaria transmission: a mathematical modelling study. Lancet Infect Dis. 2016 Apr;16(4):465-72.

20. Iman RL. Latin Hypercube Sampling. Wiley StatsRef: Statistics Reference Online; 2014. 
medRxiv preprint doi: https://doi.org/10.1101/2021.08.19.21262272; this version posted August 25, 2021. The copyright holder for this preprint (which was not certified by peer review) is the author/funder, who has granted medRxiv a license to display the preprint in

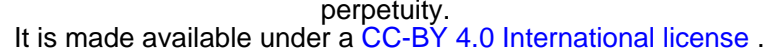

21. Stopard IJ, Churcher TS, Lambert B. Estimating the extrinsic incubation period of malaria using a mechanistic model of sporogony. Plos Comput Biol. 2021 Feb;17(2):e1008658.

22. Pfeffer DA, Lucas TCD, May D, Harris J, Rozier J, Twohig KA, et al. malariaAtlas: an R interface to global malariometric data hosted by the Malaria Atlas Project. Malar J. 2018 Oct 5;17(1):352.

23. National Malaria Control and Elimination Programme. A survey on ownership and use of long-lasting insecticidal nets and malaria treatment seeking behavior in Ethiopia (2020). Addis Ababa: Ethiopian Public Health Institute; 2020.

24. World Population Prospects. https://www.worldpop.org/. [cited 11/01/2021]; Available from:

25. Sinka ME, Pironon S, Massey NC, Longbottom J, Hemingway J, Moyes CL, et al. A new malaria vector in Africa: Predicting the expansion range of Anopheles stephensi and identifying the urban populations at risk. Proceedings of the National Academy of Sciences of the United States of America. 2020 Oct 6;117(40):24900-8.

26. Fick SE, Hijmans RJ. WorldClim 2: new 1-km spatial resolution climate surfaces for global land areas. Int J Climatol. 2017 Oct;37(12):4302-15.

27. Churcher TS, Lissenden N, Griffin JT, Worrall E, Ranson H. The impact of pyrethroid resistance on the efficacy and effectiveness of bednets for malaria control in Africa. Elife. 2016 Aug $22 ; 5$.

28. Sherrard-Smith E, Griffin JT, Winskill P, Corbel V, Pennetier C, Djenontin A, et al. Systematic review of indoor residual spray efficacy and effectiveness against Plasmodium falciparum in Africa. Nature communications. 2018 Nov 26;9(1):4982.

29. Killeen GF, Fillinger U, Kiche I, Gouagna LC, Knols BG. Eradication of Anopheles gambiae from Brazil: lessons for malaria control in Africa? Lancet Infect Dis. 2002 Oct;2(10):618-27.

30. Yared S, Gebressielasie A, Damodaran L, Bonnell V, Lopez K, Janies D, et al. Insecticide resistance in Anopheles stephensi in Somali Region, eastern Ethiopia. Malar J. 2020 May 12;19(1):180.

31. Tadesse FG, Ashine T, Teka H, Esayas E, Messenger LA, Chali W, et al. Anopheles stephensi Mosquitoes as Vectors of Plasmodium vivax and falciparum, Horn of Africa, 2019. Emerging infectious diseases. $2021 \mathrm{Feb} ; 27(2): 603-7$. 